\title{
Traditional Kinulung Craft Weaving of the Dusun Tindal of Kota Belud, Sabah
}

\author{
Salbiah binti Kindoyop ${ }^{1,}$ Noria ak Tugang ${ }^{2}$, Humin Jusilin $^{3}$ and Junior Kimwah ${ }^{4}$ \\ ${ }^{1}$ Faculty of Applied and Creative Arts, Universiti Malaysia Sarawak \\ ${ }^{21}$ Faculty of Applied and Creative Arts, Universiti Malaysia Sarawak \\ ${ }^{3}$ Borneo Heritage Research Unit, Faculty of Humanities, Arts and Heritage, Universiti Malaysia Sabah \\ ${ }^{4}$ Faculty of Humanities, Arts and Heritage, Universiti Malaysia Sabah
}

\begin{abstract}
Arts and cultural heritage is a potent reflection of the identity of a community. The art of traditional handicraft weaving in any society is dependent on the resources available in his environment and the needs of the particular community. The Dusun Tindal of Kota Belud is rich in weaving craft traditions with kinulung as one of its distinctive products. Kinulung is unique with its own specific purpose and simple design, and has been able to withstand modernisation and change. However the factors of adaptation, environmental change, and modern technological transformation could pose as threats to the traditional and heritage elements in the production of the kinulung. This study is important as a platform for the promotion of continuity and resilience of the Dusun Tindal heritage. Kinulung documentaton will clarify various aspects of the design and purpose elements of this traditional craft. The study focuses on the design and meaning presented in the kinulung weaving tradition as an object of culture in the community. Material for this study was derived from field work through observations, interviews and notations. The findings of the study indicate that the design and motif of the kinulung reflect the cultural values and local knowledge of the Dusun Tindal.
\end{abstract}

\section{Introduction}

This study on the kinulung craft aims to provide insights into an aspect of the cultural heritage of the Dusun Tindal, a majority ethnic group located predominantly in the district of Kota Belud, Sabah. Among the objectives of this study are: i) to present the local terms related to kinulung, and ii) to document the process and technique in the making of the kinulung. Basic materials used in this craft are poring (big bamboo, gigantochloa levis) and tulu (small bamboo, schizostachyum brachyladum).

In the past, kinulung was actively produced in villages around the Kota Belud district. However, although such craft is still produced nowadays, these no longer feature predominantly in the Dusun Tindal kitchen; the modern day kinulung serves a more decorative purpose rather than its original function as a food cover or food receptacle. There remains three ways to ensure the sustainability of this Dusun Tindal craft tradition: (1) by introducing the local terms and concepts related to the weaving of kinulung, (2) by the continuous production of the kinulung based on market demand, and (3) by documenting and publishing the aspects of design, technique and materials used for kinulung weaving. To ensure its continuity, the kinulung craft needs to be revitalised and made popular to the public, and the weaving techniques taught to the younger generation. 


\section{Methodology}

Photography is used in practice-based research or other research situations for the acquisition of visual data, storage or management of visual information, analysis of visual data, and the presentation of research findings. Visualisation requires drawing, diagrams, concept maps or mind maps, flow charts, storyboards, matrices, and network displays which employ colour, tone line, plane, shape, scale, and symbol. Metaphors and analogies often serve to initiate or stimulate this process of visualisation. The interview is a key method in seeking the particular opinion of others about identified research topics or areas with a purposeful conversation initiated by the interviewer and focused on content specified by the research objectives.

Data for this study was derived from (1) notes, (2) photographs, (3) sketches, and (4) voice recorder. These techniques allowed the researcher to experience and acquire a critical visual understanding of the cultural practices relayed in the interviews and during observations.

\section{Kinulung handicraft}

The kinulung name originates from the word 'okulung' which means the act of curving in Dusun Tindal. The curved shape of the kinulung is due to the material make- up which is appropriate for its function as a food cover or receptacle. The Dusun Tindal in the olden days would hang the kinulung within easy reach in the kitchen to keep or protect their food from insects, cats or dogs. During gatherings or celebrations, the kinulung becomes a tray for food presentation or preparation, its curved shape well suited as a receptacle for various food objects. Kinulung sizes vary according to the usage. For example, for food storage the size would usually be $40 \mathrm{~cm} \mathrm{x} 40 \mathrm{~cm}$. For food dishes, a larger size kinulung, around $60 \mathrm{~cm} \times 60 \mathrm{~cm}$, would be the preferred variant.

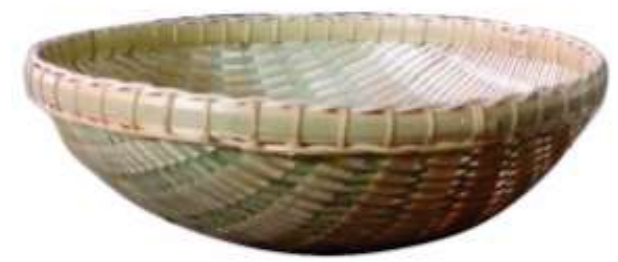

Figure 1: Kinulung design

Traditional kinulung is made from natural materials, usually tulu ${ }^{l}$ (schizostachyum brachyladum) and poring $^{2}$ (gigantochloa levis) from the bamboo family, and calamus javensis rattan. The tulu is fashioned into small strips (pinuhusan) and the poring into wider versions (pongorigi) for the weaving process. Kinulung weaving adopts an overlapping technique with strips arranged alternately in vertical and horizontal positions. The pinuhusan forms the horizontal structure of the weaving while the vertical pongorigi serves as the mainframe structure (see Figure 2).

\footnotetext{
${ }^{1}$ Tulu - a type of small bamboo with a long trunk, thin outer layer and could easily be cut open.

${ }^{2}$ Poring - a large trunk bamboo suitable for use as mainframe in weaving as it holds its structure well.
} 


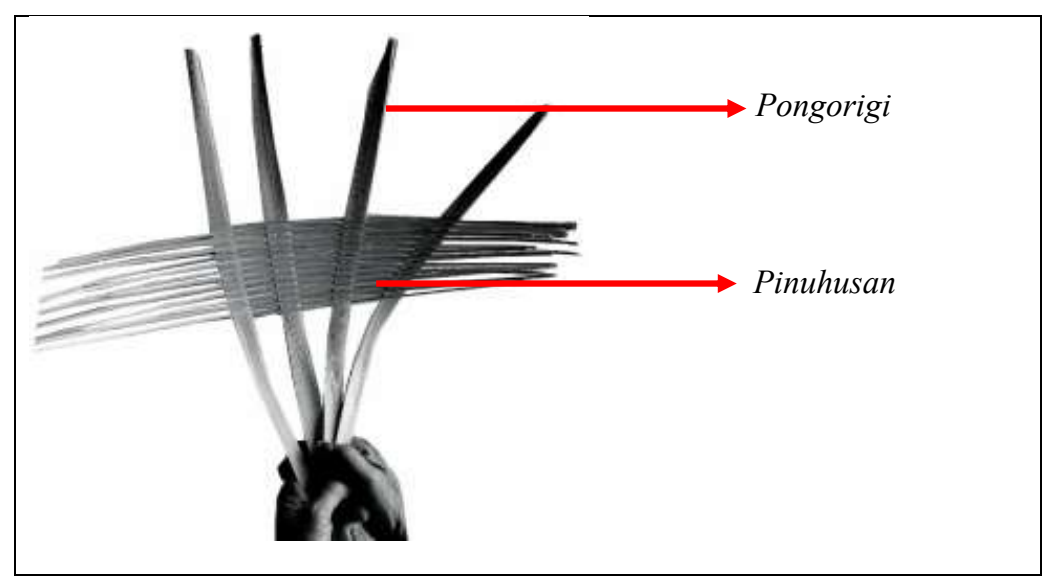

Figure 2: Kinulung weaving technique

\subsection{Process and technique of kinulung weaving}

Although kinulung weaving in itself is a fairly simple and easy technique, it is a laborious process. Weaving with small and thin bamboo strips requires skill and wisdom acquired over time or inherited from elders. The mangatu (weaving) process could be done any time of the day. Due to its small size, the pinuhusan is resistant to breakage or splitting. However the pongorigi, taken from the inner parts of the bamboo, must be moistened prior to the weaving process since it is more susceptible to damage or breakage. The supple pongorigi ensures the woven end-product is both smooth and neat.

Among the Kota Belud Dusun Tindal, the stages of kinulung production is defined according to the following sequence:
a) Mokiburuon - finding bamboo or suitable weaving material
b) Momutul - cutting the tulu and poring
c) Mamalapak - splitting and removing bamboo skin and inner part
d) Mongila - smoothening bamboo skin and inner part
e) Momuhus - trimming bamboo strips and dulung (frame)
f) Mangatu - weaving process
g) Monginsok - 'compacting' to ensure weaving is 'tight' (without gaps or space)
h) Momodulung - forming mainframe
i) Momolongkop - ensuring mainframe is neat and tied with rattan
j) Momolilit - weaving rattan on the edges of dulung or frame 
Table 1: Material and equipment used in making Dusun Tindal kinulung

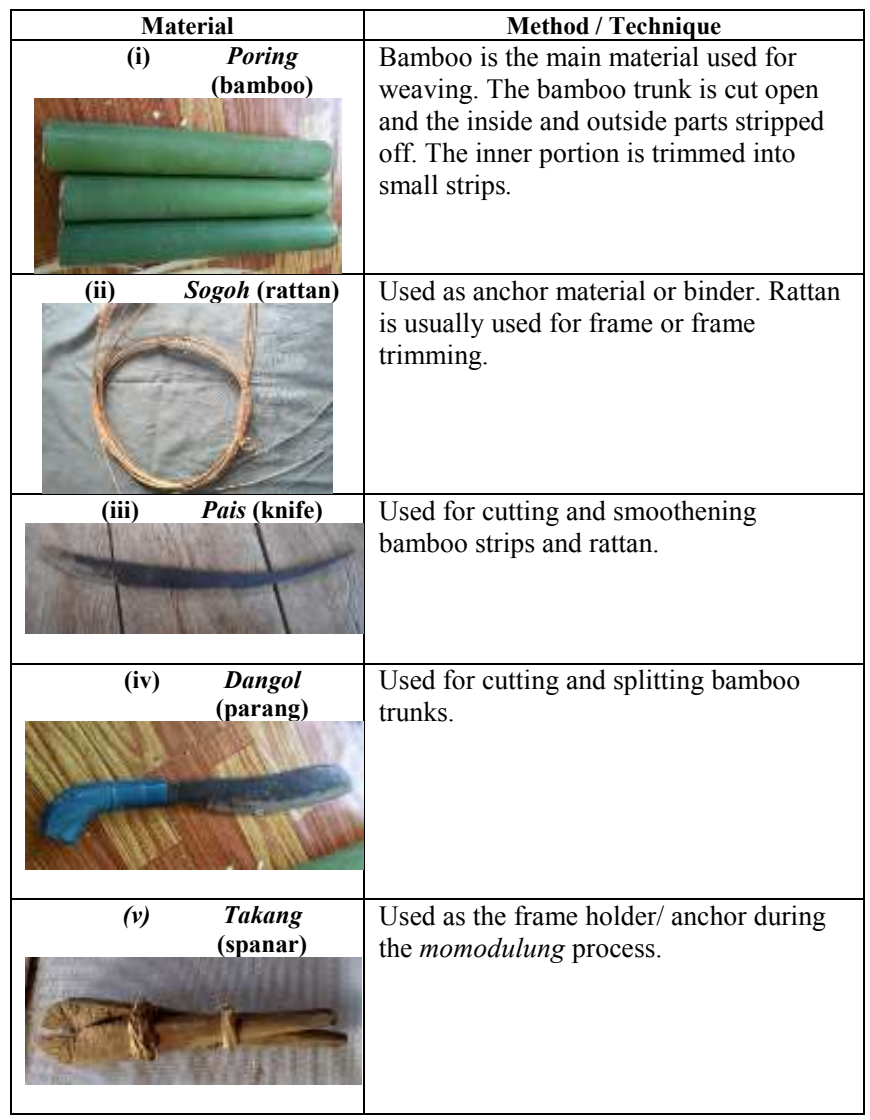


Table 2: Material and weaving techniqueof the Dusun Tindal kinulung

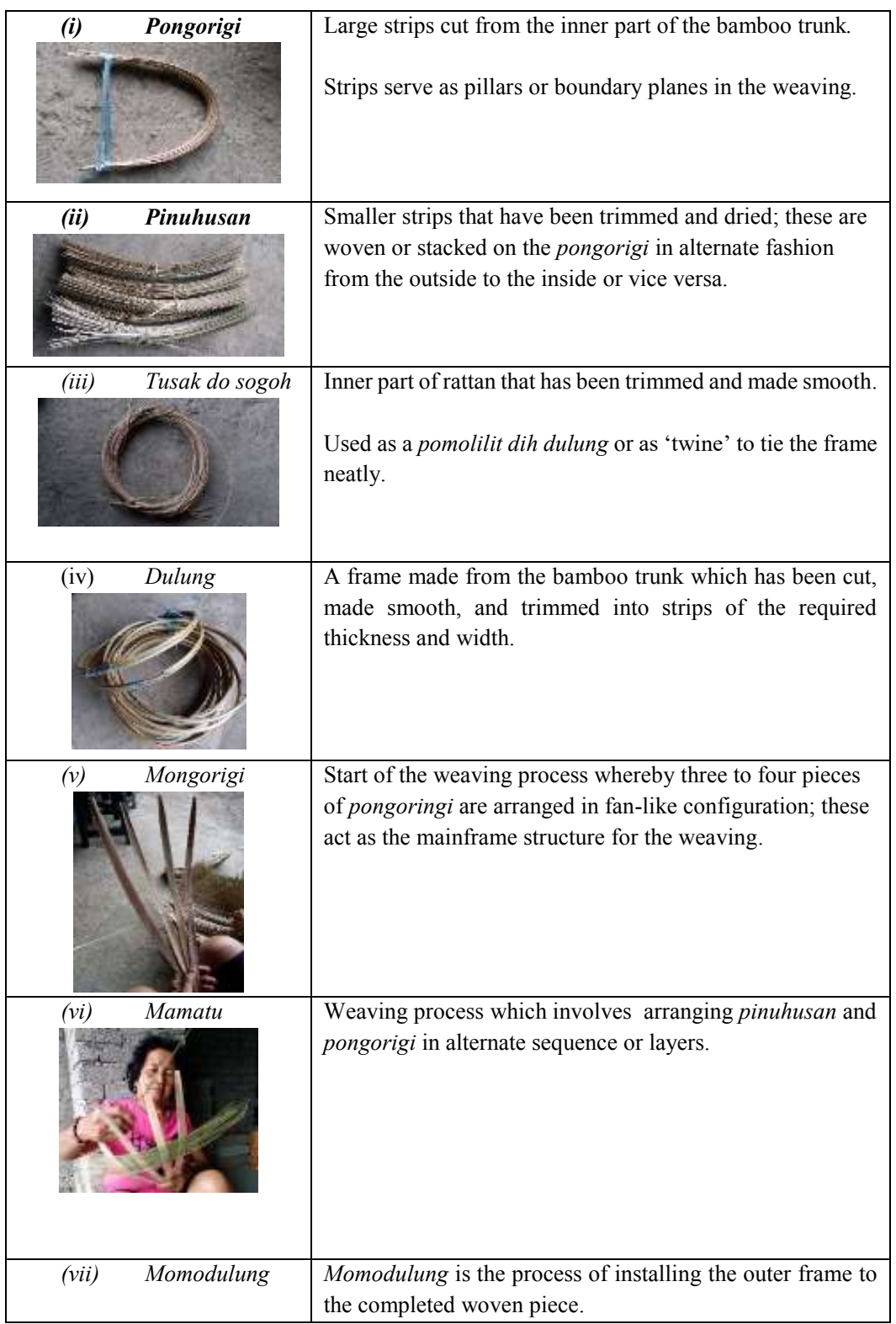




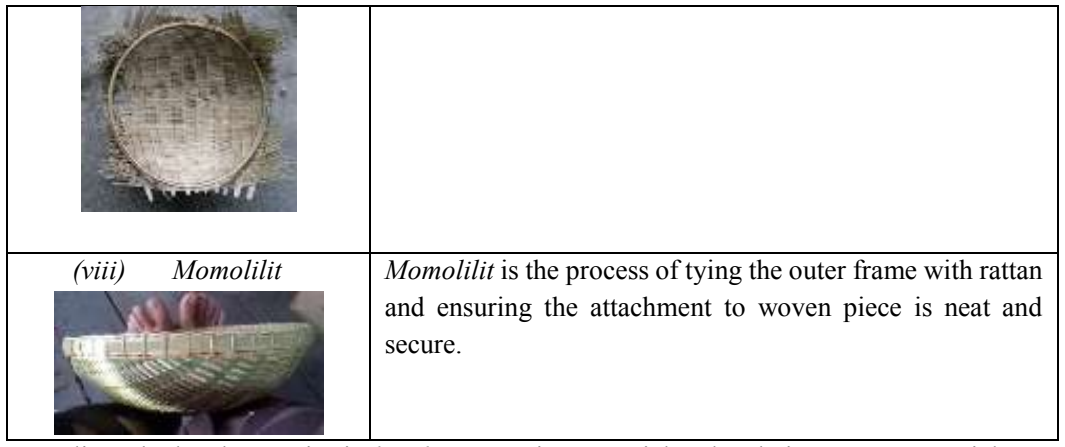

Table 2 outlines the local expertise in kinulung weaving material and technique. Four materials are essential in kinulung craft weaving: (1) pongorigi,(2) pinuhusan, (3) tusak do sogoh, and (4) dulung. These are utilised during the various stages of mongorigi, mamatu, momodulung and momolilit. According to the informants ${ }^{3}$ of this study, kinulung weaving is comparatively easier for a skilled weaver as opposed to other crafts such as basket making since the materials and weaving techniques of the former are simpler and easily learnt/ acquired.

Dusun Tindal kinulung production involves three stages: (1) the preparation of weaving materials, (2) the weaving process, and (3) the installation of frame on the completed woven craft. The process of weaving itself has two methods: the first is by positioning a large strip (pongorigi) as the backbone and interspersing this with smaller strips (pinuhusan) with the sequencing arranged in such a way so as to produce the desired size and design. According to one of the informants, ${ }^{4}$ this method could produce between 10 to 20 kinulung weavings in a day. However, the frame installation process takes a longer time since it requires more care and precision. A kinulung therefore might take about a week from commencement to completion.

Traditional kinulung weaving produces a horizontal and vertical line motif. The arrangement of bamboo strips in alternate order or sequence is presented in Figure 3(i). To obtain the kinulung curved form, the weaver will push and manipulate the materials by hand. The circumference of the kinulung frame has to be formed neatly to obtain the desired shape (see Figure 3(ii)).

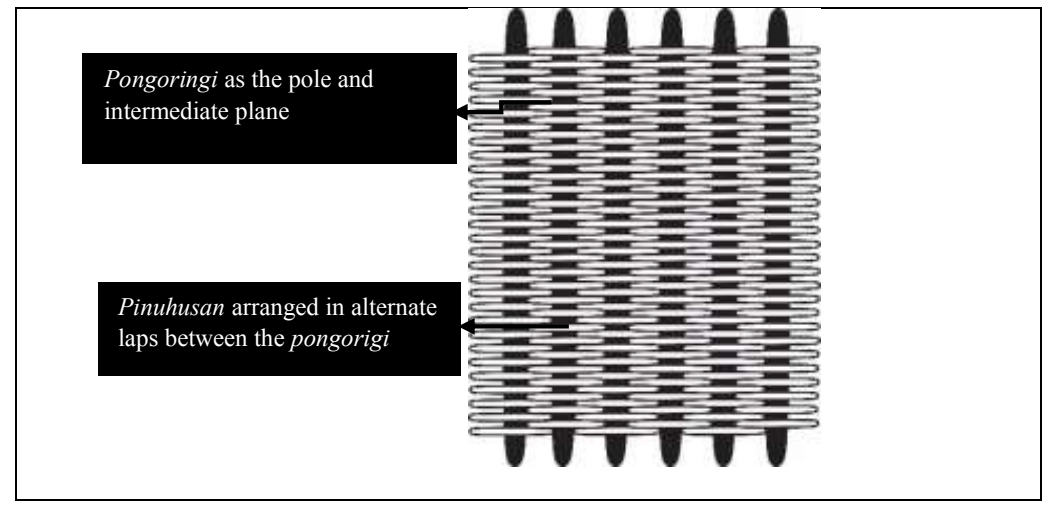

(i)

\footnotetext{
${ }^{3}$ Information from Konsimin binti Dalani (57 years old).

${ }^{4}$ Information from Sigim Binti Dalani (73 years old).
} 


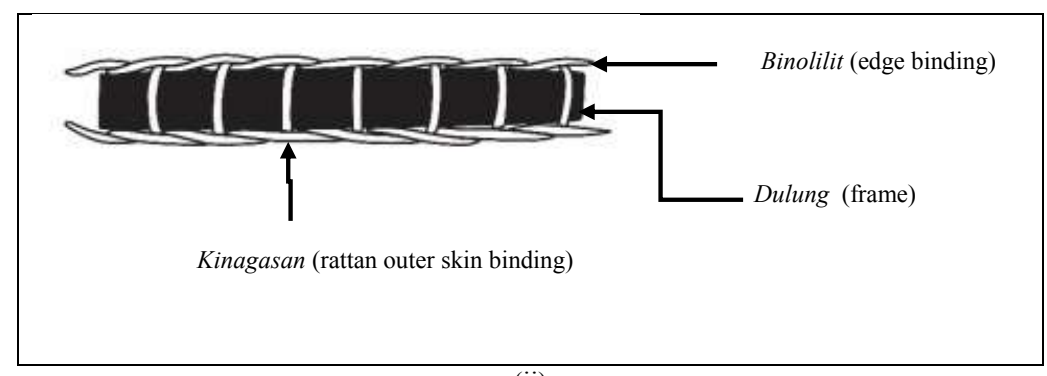

(ii)

Figure 3: Kinulung weaving technique

Figure 3 (i) shows the result of kinulung woven in a square arrangement. When the weaving is completed, the weaver will gently push and manipulate it into the desired shape. This process using palm manipulation is referred to as mongulung. Figure 3(ii) shows the binding formed on the dulung or kinulung frame. This binding, from the finely sliced skin and soft inner part of the rattan, uses the interspersing technique whereby the twine is woven inside and outside of the frame structure using either the kinagasan (knot tying technique) or binolilit (winding between the softer inner rattan part on the kinulung frame) form of attachment.

\section{Value and role of kinulung in the Dusun Tindal community}

The kinulung craft of the Dusun Tindal nowadays are used more for decorative or commercial purposes only, and no longer serve as daily features in their kitchen. Kinulung could be found in the weekly Sunday market of Kota Belud and sold more often by handicraft wholesalers. The cultural element and heritage value of the kinulung has potential in making the craft a lucrative income generator which could sustain both weavers and the tradition alike. Dusun Tindal kinulung weavers would usually sell their products to individual buyers and wholesalers with the price range between RM10 to RM15 (for the former) and RM5 to RM8 each (for the latter).

To ensure the sustainability of the Dusun Tindal kinulung, several steps could be implemented: (1) disseminate knowledge of local terms and concepts in the weaving work, and (2) ongoing craftsmanship and documentation of aspects of design, technique and manufacturing material. The perseverance and patience of craftsmen reflected in the various stages of kinulung production is indicative of the innate creativity of the Dusun Tindal community especially among the womenfolk who have been integral as a source of thought and skill in the production of traditional bamboobased crafts for generations.

\section{Conclusion}

Modern life in the era of rapid technological and digital advancement directly erodes the traditional and cultural values of a society. Modernisation has affected the art of kinulung as an integral heritage and cultural element in the Dusun Tindal community. Traditional handicraft is surely threatened with extinction if no preservation measures are put in place. The study and documentation on the design and production process of the Dusun Tindal kinulung showcases the local knowledge or expertise of the community and provides a viable channel for the dissemination of this legacy and skill for the younger generation.

\section{References}

1. Ismail Ibrahim. (2007). Warisan Motif dan Corak Etnik Sabah. Sabah: Penerbit UMS

2. Konsimin binti Dalani (57 years old), craft maker with weaving techniques. Kampung Tuguson Kota Belud. Interveiewd on 6 September 2016.

3. Siti Zainon Ismail. (1986). Rekabentuk Kaftangan Melayu Tradisi. Kuala Lumpur: Dewan Bahasa dan Pustaka Kemeterian Pelajaran Malaysia.

4. Sigim Binti Dalani (73 years old), kinulung craft maker, Kampung Bukid. Interviewed on 10 October 2016.

5. Yahya Ismail. (1998). The Cultural Heritage of Sabah. Selanggor: Dinamika Edition. 